\title{
Visualization of Learning and Memorizing Processes Using Mobile Devices: Mind Mapping and Charting
}

https://doi.org/10.3991/ijim.v14i21.18475

\author{
Lubov Vorona-Slivinskaya $(\bowtie)$ \\ Saint Petersburg State University, \\ Saint Petersburg, Russia \\ lubovvoronaslerambler.ru, Ly161@yandex.ru \\ Dmitry Bokov \\ Sechenov First Moscow State Medical University, \\ Moscow, Russia \\ Olga Li \\ Perm State Research University, Perm, Russia \\ Perm Institute of the Federal Penitentiary Service, \\ Perm, Russia
}

\begin{abstract}
The purpose of the study is to test the effectiveness of visualization of learning and memorization in the educational process in higher educational institutions. The research was carried out in St. Petersburg State University of Architecture and Civil Engineering (St. Petersburg, Russian Federation) among 1-4-year students as well as teachers. The sample included 200 students and 35 teachers. The initial and final assessment of students' professional knowledge was carried out to confirm the hypothesis of the study that the application of aforementioned methods should lead to an increase in the academic performance of the experimental group. The experimental group was introduced to visualization of learning and memorization, mainly, the use of mind maps and charts in students' professional training. Tasks were developed and used, providing for the creation of mini projects, construction layouts with charts, mental maps (reflecting the professional role of a specialist in construction and architecture fields), features and stages of design, priorities of architectural and construction activities. At the final stage, the final assessment of students' progress in vocational training and a comparative analysis of the data were carried out, conclusions were drawn about the advisability of visualizing the processes of learning and memorizing in higher education. Teachers' attitude towards the active implementation of visualization of learning and memorizing was also studied at the introductory and final stages. To determine teachers' attitude towards the active implementation of visualization of learning and memorizing, the survey was conducted. The introduction of the above-mentioned tasks gave the following results in the experimental group. Namely, there were high growth rates of students with a high level of knowledge (11.5\%), 16.4\% - with a sufficient level of knowledge and $13.7 \%$ - with an average level of knowledge; there was also a decrease in the number of students with low grades (by 16.6\%) compared to the control group at the final stage. The number of teachers with
\end{abstract}


positive-promising and positive attitudes towards visualization of learning and memorizing increased by $14.3 \%$, the number of respondents with positiveneutral attitude decreased by the same percentage, and there was not a single teacher who retained a negative attitude. The hypothesis of the study was fully confirmed. The practical value of the results lies in the possibility of using the questionnaire and developed tasks in the real educational process of modern higher education institutions.

Keywords - Educational process, higher education, learning outcomes, students, teachers

\section{$1 \quad$ Introduction}

The digital environment formed today is constantly expanding, covering all areas of human life. Increasing information consumption does not necessarily have a positive effect on cognition. There is a need to train not only students but also schoolchildren to use digital sources of information for learning and personal development. The use of digital environment and mobile devices in teaching can begin from preschool age and can be conditionally divided into the use of specialized training applications [1] and the use of mobile and online technologies to simplify and intensify the transfer of information during teaching and learning [2-4].

Various educational information sources and methods of obtaining and transmitting information are available today and it is necessary to streamline and systematize them. This tendency requires an active use of visualization methods for learning and memorizing in the modern educational process. Such tools are even more relevant for distance and blended learning [5]. Moreover, modern technologies and techniques make it possible to achieve a high level of visualization of educational material, saving time for both students and teachers [6].

Data visualization technologies and the use of infographics are most naturally included in learning, starting from preschool age, when a student is just preparing to read and perceive information in text form [7]. Effectiveness of the use of visualization and memorization technologies based on special visualization tools, for example, mind maps, depends on the involvement of teachers and their readiness to master the corresponding technologies [8]. The problem often lies in the fact that generations of native digital people, who have been born and raised in a digital environment, are better at using familiar technologies as other users. At the same time, they might not know how to use these technologies for growth and learning, which trained teachers should offer them $[8,9]$.

Despite the widespread use of mobile devices and computer visualization or information presentation tools [10], there is still relatively little research on the impact of various technologies on the real effectiveness of the learning process and on the academic performance of students. In this regard, the content of educational applications for children and effectiveness of their application are much better studied [11]. This study aims to identify the impact of computer visualization of information and tools for structuring and memorizing data (mind maps) on students' academic achievements. 


\subsection{Research outline}

The Introduction contains a brief outline of the problem of using electronic teaching aids and data visualization in teaching, as well as sets the task of research. The Literature Review section introduces research on this topic and the current achievements. The section Methods and materials describes the research method and its limitations. The Results section discusses the statistics obtained and the conclusions drawn from them. The Discussion section provides an overview of comparative and similar results from other similar studies.

\section{Literature Review}

\subsection{Informational visualization in learning}

Visualization of teaching material and application of mind-map-based memorization methods were used even before the spread of computer technology. They demonstrated a qualitative increase in the effectiveness of student learning [12]. Virtual technologies make it possible to organize information visualization in a way familiar to a modern person [13]. Modern researchers prove the need to use virtual technologies in education [14], which is confirmed by the modern goals of education, the need to motivate educational activity, development of creative and cognitive activity of students [15]. Scientists are unanimous that visualization helps to organize educational and cognitive activities of students at a high level [16] and provides training that corresponds to the 21 st century students' way of thinking [17].

Scientists believe that the main goal of visualization is to support logical operations at all stages of learning, to influence several channels of information perception by a student, and to ensure increased attention and efficiency in acquiring and memorizing new material [18].

The relevance of visualization is also growing due to the introduction of mobile learning. Scientists note the positive impact of using tablet devices in the educational process of higher education, in particular, they significantly affect attendance, academic performance, and the quality of learning, since mobile learning tools not only create a successful learning environment, but motivate students to independently acquire knowledge outside the educational institution [2] and promote progressive learning approaches [19]. Mobile learning overcomes the problems associated with access to quality educational services [20]. Mobile learning has flexible tools to complement existing technologies and expand teaching [3]. Another benefit of mobile learning is that educational apps include interactive learning materials, simulations, and learning games. These apps are fully consistent with the paradigm of collaborative learning, they contribute to the realization of reflective exercises in training sessions [4], they are a means of sustainable development, they also expand the access to information without space-time restrictions [21]. Scientists from different countries consider the prospects and problems of mobile education and e-learning both in developed educational systems and in backward ones [22], while calling mobile learning an important promising component of educational technologies that affects the development of technological infrastructure [23]. 
With the increasing popularity of mobile learning, it becomes necessary to promote digital educational software and the responsible attitude of education seekers to the use of mobile devices in the educational process [24]. Despite the growing use of mobile devices in education, researchers believe that mobile learning should be optimally combined with traditional educational approaches that can be significantly enriched by mobile means [25]. Empirical studies prove the effectiveness of mobile devices both in learning and in combination of learning activities and informal communication [26].

The visualization of learning and memorization processes is considered a condition for the development of thinking [27] and a compact presentation of various kinds of information. The visualization can be implemented for key educational tasks [12].

\subsection{Mind maps as information visualization technology}

Mind maps are considered the main means of visualization. Modern researchers point out the uniqueness of this method, determine reasons, possibilities, prospects for their use in higher education [28]. Mind mapping is a productive tool of visualizing any information [29]. Moreover, this presentation of information simultaneously reflects various correlations between concepts or components of the area under consideration.

Some researchers and practicing scientists consider the use of video fragments as part of the visualization of learning and memorizing, which can have a positive effect on the quality of knowledge and the motivation to learn [30] as well as contribute to the development of systematization and structuring of skills and creativity [31]. They also consider the use of flash technologies as a means of visualization [32]; augmented reality, which visualizes abstract concepts using 3D images [33].

Timeline and scribing are also effective means of visualization that simultaneously consider the main priorities of modern teaching methods and the needs of the network community [34]. There are also infographics, Glogster, ChroNOline, which, in addition to providing knowledge, also contribute to the development of student's personality [35]. Visualization is considered a means of accessible presentation of educational material, facilitating its perception, versatile comprehension of the material, development of thinking and skills of non-standard problem-solving [5].

The largest number of studies on visualization of learning and memorizing is devoted to mind maps, which are considered as a means of developing logical thinking [36], innovative thinking, motivation and development of students' thinking throughout life [37] as well as a means of collective knowledge construction [6]. The potential of this tool is very wide, it allows one to present concepts and the relationship between them simultaneously. On the other hand, this vision can be expanded and refined on numerous nested levels with text, video, sound files, etc., tied to each individual concept in the mind-map graph [17]. This tool assumes both the simplest and very complex and multilevel options for presenting information.

The methodology of using various types of mind maps in teaching, in particular, concept mind maps, is currently developing [38]. The pedagogical experiments for comparing the effectiveness of teaching are being conducted with and without mental maps. The opportunities for students to assess the effectiveness of mind maps in the modern educational process are also being provided [39]. 
With pedagogical experiments, researchers establish new ways of visualization, which they successfully test on practice, in particular, animated hints, which increase students' motivation, make the learning process creative and contribute to the development of students' creative abilities [40]. Scientists offer real examples of using teaching visualization tools, namely, infographics for studying design [41] and share their own developments in educational material visualization [42].

\subsection{Mind maps in variety specializations}

The possibility of using educational static and dynamic visualization to promote health and science [43], the role of visualization for increasing teaching effectiveness [44], and the dependence of teaching effectiveness on the quality of material visualization [45] were pointed out.

Some studies highlight the importance of charts as means of visualizing, which can be used not only for technical specialties, but also arts and humanities [46]. Charting is the use of graphical data visualization using mobile or computer apps. Charting has perspectives in statistical graphics for data visualization [10].

There are several controversial works that prove the mediocre effectiveness of using such a visualization tool as mind maps in educational activities, where preference is given to interviewing students as an effective means of measuring educational achievement [47].

Online co-education, social online interactions are considered as prospects for further visualization of the educational process, and the development of students' reflexivity is its main advantage [48]. Advanced scientists are currently developing, successfully testing and implementing interactive visualization tools for learning management systems [49].

Visualization is relevant in view of the fact that the virtual environment and augmented reality help to cope with problems that cannot be solved by traditional methods. Therefore, teachers should work on improving students' visualization skills [50]. Visualization motivates students to learn, makes them more collaborative and develops critical skills [51]. Students can use visualization tools provided by teachers to better understand the learning process and acquire new skills [13]. Scientists contrast visual models using manipulation and computer software with traditional cramming and memorizing [52].

All analyzed scientific works emphasize the importance of introducing visualization of learning and memorizing that is one of the key challenges of modern higher education.

\subsection{Task setting}

The analyzed scientific sources prove the need to introduce visualization of learning and memorizing, determine the influence of visualization of learning on educational achievements. It is necessary to establish clear relationship between the visualization of learning and memorizing and students' educational achievements, their motivation to acquire professional knowledge, skills and abilities.

The purpose of the study is to test the effectiveness of visualization of learning and memorization in the educational process of higher institutions. 
The study aims to:

- Analyze scientific works on the visualization of learning and memorizing.

- Develop and test the tasks for visualization of learning and memorizing.

- Determine the impact of visualization of learning and memorizing processes on learning outcomes.

- Compare the obtained data with the available foreign experience, determine the common and distinctive features.

- Draw conclusions about the effectiveness and further expediency of visualization of learning and memorizing in higher education.

Novelty of the research refers to the development of a questionnaire on teachers' attitude to the active implementation of visualization of learning and memorizing as well as tasks for visualizing educational material related to the specialty that studentsrespondents receive.

\section{$3 \quad$ Methods and Materials}

\subsection{Research design and sample}

The study was conducted at St. Petersburg State University of Architecture and Civil Engineering. This is an appropriate and convenient institution to demonstrate the effectiveness of visualization tools, since technical specialties and graphical technical presentation of information prevail here. The respondents were 1-4-year students (control and experimental groups). The total number of respondents was 200, 100 participants in experimental group and 100 - in control group. Students of different course year were selected for the study to track the impact of visualization tools on respondents with different background.

The hypothesis of the study is that the visualization of learning and memorizing in higher education has a positive effect on students' progress, contributes to students' motivation for educational and cognitive activities.

The experiment was carried out for 3 months. Both groups studied under the same current university programs. The experimental group undergone active introduction of visualization of learning and memorizing, mainly, the use of mind maps and charts in the professional training of students.

Based on a preliminary analysis of the academic success and level of assessment of students before the start of the experiment participants' academic performance was divided into four levels: high, sufficient, medium, and low. The students' results were assessed with tests and situation-based assignments in the disciplines of professional training developed by teachers of the control and experimental groups.

The teachers' attitude to the active implementation of visualization of learning and memorizing was studied using an online survey based on the questionnaire specially developed by the authors (see Table 1 below). 35 teachers completed questionnaires and submitted them by email.

At the final stage, the final assessment of students' progress in vocational training and a comparative analysis of the data were carried out, conclusions were drawn 
about the advisability of visualizing the processes of learning and memorizing in higher education. Based on the results of the initial and final study of student performance for each year of study, the percentage of participants in four levels of professional improvement was determined: High, Sufficient, Average and Low. The impact of visualization and memorization tools on the academic performance of students was determined by the change in the number of participants in these groups.

\subsection{Ethical issues}

All study participants were recruited on the basis of voluntary consent and guarantees of non-disclosure of their personal information. When processing learning outcomes, all participants received unique random identification codes by which the information associated with them was identified. Thus, no personal data of the participants was recorded or used.

Table 1. Questionnaire for determining teachers' attitude towards active implementation of visualization of learning and memorizing

\begin{tabular}{|c|c|c|c|c|}
\hline Statement/Answer & Yes & Partly & No & $\begin{array}{c}\text { Difficult } \\
\text { to } \\
\text { answer } \\
\end{array}$ \\
\hline \multicolumn{5}{|l|}{ 1. I often practice visualization in my own teaching activities } \\
\hline \multicolumn{5}{|l|}{$\begin{array}{l}\text { 2. I am fully aware of the need to visualize the learning and memorizing } \\
\text { material }\end{array}$} \\
\hline \multicolumn{5}{|l|}{$\begin{array}{l}\text { 3. I am able to recreate different ways of data visualization in real teaching } \\
\text { practice }\end{array}$} \\
\hline \multicolumn{5}{|l|}{$\begin{array}{l}\text { 4. I can develop and implement an original methodological model of the } \\
\text { lesson using different visualization tools for educational material }\end{array}$} \\
\hline \multicolumn{5}{|l|}{$\begin{array}{l}\text { 5. I systematically work on improving my own materials on the visualization } \\
\text { of information }\end{array}$} \\
\hline \multicolumn{5}{|l|}{$\begin{array}{l}\text { 6. I can share my own experience on visualization of learning and memoriz- } \\
\text { ing material with my colleagues }\end{array}$} \\
\hline \multicolumn{5}{|l|}{$\begin{array}{l}\text { 7. I involve students in the search, selection and development of mind maps } \\
\text { and other visualization tools }\end{array}$} \\
\hline \multicolumn{5}{|l|}{$\begin{array}{l}\text { 8. I believe that the means of visualization develop thinking, memory, crea- } \\
\text { tivity of students }\end{array}$} \\
\hline \multicolumn{5}{|l|}{$\begin{array}{l}\text { 9. I have a large selection of student works using visualization tools for } \\
\text { learning and memorizing }\end{array}$} \\
\hline \multicolumn{5}{|l|}{$\begin{array}{l}\text { 10. Students positively respond about tools and methods I use to visualize the } \\
\text { learning and memorizing material within the training sessions }\end{array}$} \\
\hline \multicolumn{5}{|l|}{$\begin{array}{l}\text { 11. Visualization of learning and memorizing material is a guarantee of high } \\
\text { educational results }\end{array}$} \\
\hline $\begin{array}{l}\text { 12. Visualization of learning and memorizing material helps to increase } \\
\text { students' motivation for studying }\end{array}$ & & & & \\
\hline
\end{tabular}

\subsection{Results' implementation}

For each answer of a respondent, the following points were given: 'yes' - 3 points, 'partially' - 2 points, 'no' - 0 points, 'difficult to answer' - 1 point. According to the 
points scored, teachers' attitude to the active implementation of visualization of learning and memorizing was determined.

Positive-promising attitude: $30-36$ points: Teacher uses in everyday teaching practice the means of visualization of learning and memorizing materials, involves students in collaboration when developing various means of visualization of educational information.

Positive attitude: $24-29$ points: Teacher uses the means of visualization of learning and memorizing material, and is aware of its influence on the success of students and their motivation for learning and cognitive activity.

Positive-neutral attitude: $18-23$ points: Teacher recognizes the need of visualization of learning and memorizing materials but is not professionally ready for this work, although he/she is working for self-improvement in this direction.

Negative attitude: Less than 17 points: Teacher has a negative or indifferent attitude to the visualization of learning and memorizing material, he/she is not ready to create or use these materials and is not able to involve students in this work.

All participants were alerted to the goals of the research. They positively perceived the introduction of visualization materials into the educational process and had no objections. The administration of the educational institution met the needs of the participants in the experiment and financed the access of teachers and students to paid services and resources for creating visualization materials.

\subsection{Statistical analysis}

All the respondents were questioned using Google Forms. To process the results, a Google Table (integrated with Google Forms) was used. The results of the questionnaire are presented in the table and diagram.

\subsection{Research limitations}

Age of the respondents: Students - 18-23, teachers: 29-48 years old. The research was carried out within the educational process and was limited in time. In the course of the study, visualization materials were introduced into an already modeled educational process without any adjustments to educational programs.

\section{$4 \quad$ Results}

In the control groups, the educational process took place as usual, and in the experimental groups, the visualization of learning and memorizing material was actively introduced through the use of mental maps and charting with the help of mobile platforms. Students have been assigned creative tasks that develop thinking, and also encourage them to use already acquired professional knowledge, skills and abilities.

Teachers involved students at various stages of training in the implementation of visualization and the use of mobile learning tools. For example, teachers used mind maps made by Google's online applications to present educational material, as well as 
created mind maps with a $3 \mathrm{~d}$ effect using the Mind Meister app. Students also received individual mini-projects to create mind maps for future classes. They had the opportunity to develop mind maps in a creative way using the Mapul app.

Based on self-study material, students created and shared reports using their mobile devices with Canva presentations and Venn gage.

The following tasks were assigned:

1. To create a mini-project of one's dream home using Piktochart infographics and share it with one's classmates on social networks.

2. To create a mind map that reflects the knowledge and skills of a modern competitive architect using Google app.

3. To fill in the mind map, indicating the main stages of design and identifying the key word hidden in the map.

4. To make a mental map reflecting the main priorities of architectural and construction activities, using the Mind Meister, share it with one's classmates on social networks and send to the teacher via Viber.

5. To design the layout of the future city using $3 \mathrm{D}$ modeling and charting with the help of Google Charts and Piktochart.

All this makes it possible to involve students in the creation of didactic tools for the visualization of learning, as a result, it contributes to their professional improvement, the development of a creative vision of their own future in the technical direction, and also strengthens their learning and cognitive motivation.

This approach had a positive impact on the educational results of the students from experimental groups. The data of the input and output monitoring of educational results of the control and experimental groups of all years of study at the introductory and final stages of the research are shown in Table 2.

Table 2. Results of students' professional knowledge monitoring

\begin{tabular}{|c|c|c|c|c|c|c|c|c|c|}
\hline \multirow{3}{*}{$\begin{array}{c}\text { Stages of } \\
\text { research/ } \\
\text { Number of } \\
\text { respondents }\end{array}$} & \multicolumn{8}{|c|}{ Level of knowledge } & \multirow{3}{*}{ Total } \\
\hline & \multicolumn{2}{|c|}{ High } & \multicolumn{2}{|c|}{ Sufficient } & \multicolumn{2}{|c|}{ Average } & \multicolumn{2}{|c|}{ Low } & \\
\hline & Number & $\%$ & Number & $\%$ & Number & $\%$ & Number & $\%$ & \\
\hline \multicolumn{10}{|c|}{ I year } \\
\hline \multicolumn{10}{|c|}{ CG-1 } \\
\hline $\mathrm{I}$ & 0 & 0 & 5 & 20 & 7 & 28 & 13 & 52 & 25 \\
\hline $\mathrm{F}$ & 0 & 0 & 6 & 24 & 8 & 32 & 11 & 44 & 25 \\
\hline \multicolumn{10}{|c|}{ EG-1 } \\
\hline $\mathrm{I}$ & 0 & 0 & 5 & 20 & 8 & 32 & 12 & 48 & 25 \\
\hline $\mathrm{F}$ & 2 & 8 & 8 & 32 & 12 & 48 & 3 & 12 & 25 \\
\hline \multicolumn{10}{|c|}{ II year } \\
\hline \multicolumn{10}{|c|}{ CG-2 } \\
\hline $\mathrm{I}$ & 1 & 4.2 & 8 & 3.6 & 11 & 46.2 & 4 & 16.8 & 24 \\
\hline $\mathrm{F}$ & 2 & 8.4 & 9 & 37.8 & 11 & 46.2 & 2 & 8.4 & 24 \\
\hline \multicolumn{10}{|c|}{ EG-2 } \\
\hline I & 2 & 7.6 & 10 & 38 & 8 & 30.4 & 6 & 22.8 & 26 \\
\hline $\mathrm{F}$ & 5 & 19 & 15 & 57 & 5 & 19 & 1 & 3.8 & 26 \\
\hline
\end{tabular}


Paper-Visualization of Learning and Memorizing Processes Using Mobile Devices: Mind Mapping..

\begin{tabular}{|c|c|c|c|c|c|c|c|c|c|}
\hline \multicolumn{10}{|c|}{ III year } \\
\hline \multicolumn{10}{|c|}{ CG-3 } \\
\hline I & 1 & 4 & 6 & 24 & 15 & 60 & 3 & 12 & 25 \\
\hline $\mathrm{F}$ & 1 & 4 & 8 & 32 & 13 & 52 & 3 & 12 & 25 \\
\hline \multicolumn{10}{|c|}{ EG-3 } \\
\hline I & 1 & 4 & 6 & 24 & 14 & 56 & 4 & 16 & 25 \\
\hline $\mathrm{F}$ & 4 & 16 & 10 & 40 & 9 & 36 & 2 & 8 & 25 \\
\hline \multicolumn{10}{|c|}{ IV year } \\
\hline \multicolumn{10}{|c|}{ CG-4 } \\
\hline I & 3 & 12.9 & 11 & 47.3 & 8 & 34.4 & 1 & 4.3 & 23 \\
\hline $\mathrm{F}$ & 3 & 12.9 & 13 & 55.9 & 7 & 30.1 & 0 & 0 & 23 \\
\hline \multicolumn{10}{|c|}{ EG-4 } \\
\hline I & 3 & 11.1 & 10 & 37 & 12 & 44.4 & 2 & 7.4 & 27 \\
\hline $\mathrm{F}$ & 7 & 25.9 & 15 & 55.5 & 14 & 51.8 & 0 & 0 & 27 \\
\hline
\end{tabular}

According to Table 2, at the final stage of the research there was a large increase in the number of persons with a high level of knowledge (by $8 \%$ in the first, by $11.4 \%$ in the second, by $12 \%$ in the third and by $14.8 \%$ in the fourth year), a sufficient level of knowledge (by $12 \%$ in the first, by $19 \%$ in the second, by $16 \%$ in the third and by $18.5 \%$ in the fourth year). There was also an increase in the average level of knowledge (by $16 \%$ in the first, by $11.4 \%$ in the second, by $20 \%$ in the third and by $7.4 \%$ in the fourth year), as well as a decrease of respondents with a low level of educational results (by $36 \%$ in the first, by $19 \%$ in the second, by $4 \%$ in the third and by $7.4 \%$ in the fourth year). This proves the effectiveness of the work system proposed by the authors. There were no statistically significant changes in the results of the control group.

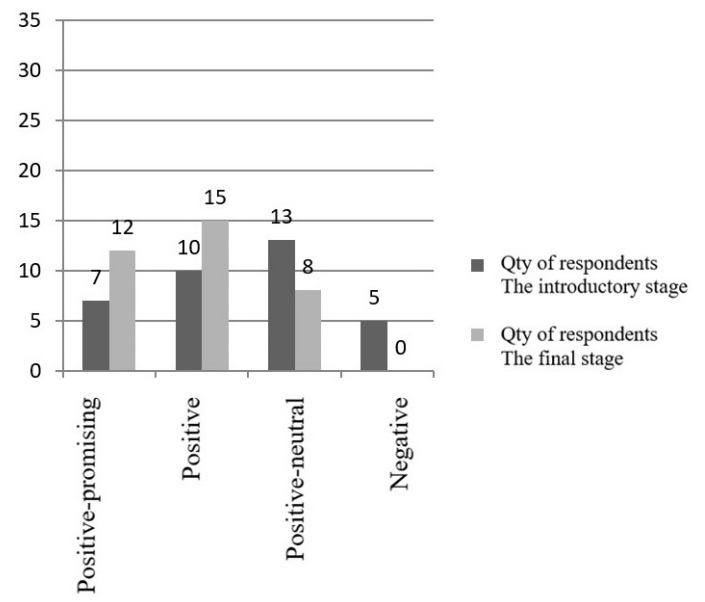

Fig. 1. The attitude of teachers towards active introduction of visualization of learning and memorizing material 
The given diagram (Fig. 1) proves that in the process of active use of visualization tools, teachers' attitude to the visualization of learning and memorizing material has transformed. Thus, at the final stage of the study, the number of people with positivepromising and positive attitudes increased by $14.3 \%$, the number of respondents with a positive-neutral attitude decreased by the same percentage, and there was not a single teacher who would retain a negative attitude towards visualization of learning and memorizing material.

\section{Discussion}

The similar study was conducted among high school students in several schools in Indonesia. Similarly, two classes were selected from each of the institutions, one used visualization tools, and the second did not. This research has confirmed the effectiveness of learning process visualization [53]. The study among Arab students emphasizes the use of mind maps as a means of visualizing learning material.

Therefore, it has been proven that the use of mind maps helps students to generalize long-term lessons and increases students' participation in lessons and peer communication, which helps to consolidate scientific theories and concepts. Moreover, this visualization method had a positive effect on the emotional state of students, as they became more responsive and motivated due to positive contribution to the learning environment [54]. This research is similar to the present one in the idea of students' involvement in the creation of tools for visualizing educational information. The study by Ikhsan et al. [55] has found that the use of visualization techniques simplifies memorization and relieves students' anxiety and gives confidence in connection with improved academic success, which is consistent with the results of the present study.

Another study has set up the idea of a harmonious combination of various types of visual information, due to which the quality of didactic materials used in the classroom should be achieved. Namely, this is the use of interactive multimedia and visual technologies that consider personal and individual characteristics of students [45]. The developed visualization tasks are also focused on the individual creativity of students.

Finnish and Italian researchers carried out the experiment that involved the development and implementation of effective visualization tools. The research was conducted at the intelligent information systems laboratory of the Tampere University of Technology (Finland). The researchers analyzed student activity with automatically recorded user data and created interactive visualizations. It was not the structure of information for memorization and not the information itself that was visualized to facilitate learning, as in the case of the present study, but the learning outcomes for changing pedagogical methods. The latter provide valuable information about the learning process and student participation in training courses. At the Sapienza University (Italy), a tool has been developed that expands the navigation and search options in a forum with the help of a thematic paradigm. The tool analyzes the content of a 
forum and automatically identifies topics for discussion [49]. These tools are aimed at visualizing education processes and organizing the use of teaching methods.

Indonesian study, different in purpose, used mind mapping to measure students' logical thinking based on criteria such as knowledge, communication, thinking, and application. This study proved that the use of mind maps improves the quality of learning [56] as well as students' performance, as in the experiment conducted in the present study. Unlike the present research, these tools are technical, they do not require creativity, critical thinking, and hardly effect motivation and learning outcomes.

Of fundamental importance is the scientific study conducted in secondary schools in Indonesia. It involved the development and use of a virtual reality laboratory, since it allowed manipulating objects on a virtual scene similarly to the real world. The effectiveness of such programs and mobile applications has already been proven for children $[11,18]$. The virtual reality lab was designed to improve students' critical thinking. The respondents to this study were divided into three groups: the first group studied objects using a virtual reality laboratory; the second used virtual reality and a real laboratory; the third worked only in real conditions. The results showed the high quality of laboratory integrated hybrid learning with virtual reality. The experiment proved a significant difference in the critical thinking of students of the first two groups compared to the third one. Students of the first two groups were better at critical thinking compared to the third group [55].

The results prove the efficiency of using both visualization tools separately and in combination with traditional teaching methods, so-called hybrid learning model, which contains traditional and innovative methods, including visualization tools. Thus, the hybrid learning model has a positive effect on learning outcomes, motivation of educational and cognitive activities, promotes creativity, logical and critical thinking of students.

Most studies on visualization of learning and memorizing emphasize on its positive effect on learning outcomes, creativity, critical thinking, motivation to study and development of skills and abilities.

The role of the current research is in the expansion of ideas about visualization of educational processes in higher education.

\section{Conclusion}

During the research a questionnaire was proposed to determine the attitude of teachers to the introduction of visualization of learning and memorizing material, the content of which relates to students' specialty. 3-month training was conducted with the use of information visualization by the mind-map method in experimental group. After the introduction of tasks at the final stage, compared with the introductory one, in the experimental group there were large rates of increase in a number of people with a high level of knowledge, a sufficient level of knowledge, an average level of knowledge, as well as a decrease of respondents with a low level of educational results. There were no statistically significant changes in the results of the control group. Besides, at the final stage of the research, the number of teachers with a posi- 
tive-promising and positive attitude to the visualization of learning increased by $14.3 \%$, the number of respondents with a positive-neutral attitude decreased by the same percentage, and there was not a single teacher who retained a negative attitude to the visualization of learning and memorizing material. These results prove the effectiveness of the work system proposed by the authors and demonstrate effectiveness of information methods visualization for improving academic performance. The practical value of the results of scientific research lies in the possibility of using the questionnaire and tasks developed by the authors in the real educational process of a modern higher education institution, which wants to maintain a ranking position in the market of educational service providers.

\section{Acknowledgement}

The work of the second author (Bokova D.O.) was financially supported by "Russian Academic Excellence Project 5-100" (Sechenov University).

\section{References}

[1] Kalogiannakis, M., Papadakis, S. (2019). Evaluating pre-service kindergarten teachers' intention to adopt and use tablets into teaching practice for natural sciences. International Journal of Mobile Learning and Organization, 13(1): 113-127. https://doi.org/10.1504/ijm $\underline{10.2019 .10016617}$

[2] Wilkinson, K., Barter, P. (2016). Do mobile learning devices enhance learning in higher education anatomy classrooms? Journal of Pedagogic Development, 6(1): 14-23.

[3] Klimova, B., Poulova, P. (2016). Mobile learning in higher education. Advanced Science Letters, 22(5-6): 1111-1114. https://doi.org/10.1166/asl.2016.6673

[4] Leinonen, T., Keune, A., Veermans, M., Toikkanen, T. (2016). Mobile apps for reflection in learning: A design research in K-12 education. British Journal of Educational Technology, 47(1): 184-202. https://doi.org/10.1111/bjet.12224

[5] Berman, N.D. (2018). Visualization as an effective teaching tool. Postulate, 4: 1-5.

[6] Stokhof, H., De Vries, B., Bastiaens, T., Martens, R. (2019). Mind map our way into effective student questioning: A principle-based scenario. Research in Science Education, 49(2): 347-369. https://doi.org/10.1007/s11165-017-9625-3

[7] Papadakis, S., Kalogiannakis, M. (2017). Mobile educational applications for children: what educators and parents need to know. International Journal of Mobile Learning and Organization, 11(3): 256-277. https://doi.org/10.1504/ijmlo.2017.085338

[8] Papadakis, S., Kalogiannakis, M., Zaranis, N. (2017). Designing and creating an educational app rubric for preschool teachers. Education and Information Technologies, 22(6): 3147-3165. https://doi.org/10.1007/s10639-017-9579-0

[9] Papadakis, S. (2018). Evaluating pre-service teachers' acceptance of mobile devices with regards to their age and gender: a case study in Greece. International Journal of Mobile Learning and Organization, 12(4): 336-352.https://doi.org/10.1504/ijmlo.2018.10013372

[10] Nolan, D. (2016). Teaching and Learning Data Visualization: Ideas and Assignments. The American Statistician, 4: 1-17. 
[11] Papadakis, S., Vaiopoulou, J., Kalogiannakis, M., Stamovlasis, D. (2020). Developing and Exploring an Evaluation Tool for Educational Apps (ETEA) Targeting Kindergarten Children. Sustainability, 12(10): 4201. https://doi.org/10.3390/su12104201

[12] Kuzmich, V.V., Trukhan, N.S. (2017). Information visualization as a means of improving the learning process Current issues of vocational education: abstracts of the I Int. scientific-practical conf. (Republic of Belarus, Minsk, May 18, 2017). Minsk: BSUIR, pp. 128130.

[13] Makarova, E.A., Makarova, E.L., Varaksa, A.M. (2017). Education process visualization in metacognition development and sustainability. International Journal of Cognitive Research in Science, Engineering and Education, 5(2): 65-74. https://doi.org/10.5937/ijcrsee1 $\underline{702065 \mathrm{a}}$

[14] Kuptsov, A.I., Kuptsov, S.A., Khairullin, R.Z., Bogach, V.V. (2016). Development and use of virtual reality technologies in learning processes. Technological University Bulletin, 19(4): 100-101.

[15] Muravyeva A.A., Oleynikova O.N., Aksenova N.M., Dorozhkin E.M. (2019). National Qualifications System in Russia - an Epistemological Perspective. The Education and science journal, 21(4): 92-114.

[16] Soroka, O.G., Vasilyeva, I.N. (2015). Visualization of educational information. University of Pedagogical Self-Education, 12: 1-12.

[17] Palieva, T.V., Kononenko, O.V. (2018). Cognitive visualization technologies as a means of generalization, systematization and memorization of theoretical information by students. Vesnik MDPU name I. P. Shamyakina, 1(51): 108-112.

[18] Mosina, Y. (2020). The role of visualization in education process. Innovation in education, 11(2): 203-208.

[19] Chang, C.Y., Lai, C L., Hwang, G.J. (2018). Trends and research issues of mobile learning studies in nursing education: A review of academic publications from 1971 to 2016 . Computers \& Education, 116: 28-48. https://doi.org/10.1016/j.compedu.2017.09.001

[20] Chaka, J.G., Govender, I. (2017). Students' perceptions and readiness towards mobile learning in colleges of education: a Nigerian perspective. South African Journal of Education, 37(1): 1-12. https://doi.org/10.15700/saje.v37n1a1282

[21] Artamonov, V., Vorona-Slivinskaya, L., Medvedeva, A. (2016). The algorithm of sustainable development of organizations: a social aspect. Procedia engineering, 165: 1192-1196. https://doi.org/10.1016/i.proeng.2016.11.838

[22] Koissaba, B.R. (2017). Education for all: prospects and challenges of mobile schools, mobile education, and e-learning for the nomadic pastoralists in Kenya. In Conference: Kenya Scholars and Studies Association, pp. 1-27.

[23] Al-Emran, M., Elsmere, H.M., Shaalan, K. (2016). Investigating attitudes towards the use of mobile learning in higher education. Computers in Human behavior, 56: 93-102. https://doi.org/10.1016/j.chb.2015.11.033

[24] Porter, G., Hampshire, K., Milner, J., Munthali, A., Robson, E., De Lannoy, A., Bango, A., Gunguluza, N., Mashiri, M., Tanle, A., Abane, A. (2016). Mobile phones and education in Sub-Saharan Africa: From youth practice to public policy. Journal of International Development, 28(1): 22-39. https://doi.org/10.1002/jid.3116

[25] Pimmer, C., Mateescu, M., Gröhbiel, U. (2016). Mobile and ubiquitous learning in higher education settings. A systematic review of empirical studies. Computers in human behavior, 63: 490-501. https://doi.org/10.1016/j.chb.2016.05.057

[26] So, S. (2016). Mobile instant messaging support for teaching and learning in higher education. Internet and Higher Education, 31: 32-42. https://doi.org/10.1016/j.iheduc.2016.06. $\underline{001}$ 
[27] Shepelevich, E.I. (2020). Visualization of the didactic process when working with foreign students of the preparatory department. Actual problems of pre-university training, 1: 202204.

[28] Gomzyakova, N.N. (2017). Formation of memorization techniques in students with the help of mind-maps. Education, Science, Culture: Traditions and Modernity: Materials of the VII All-Russian Scientific and Practical Conference (March 2-3, 2017). Anapa branch of the Moscow Pedagogical State University. Krasnodar: Publishing House - South.

[29] Nadeem, D., Stoyanova, S., Koper, R. (2010). Using concept mapping for needs analysis for a social support system in learning network. International Journal of Interactive Mobile Technologies, 5(1): 41-46. https://doi.org/10.3991/ijim.v5i1.1520

[30] Voznyuk, O.I. (2019). Effective visualization techniques in teaching a foreign language (video fragments). Topical issues of Germanic philology and linguodidactics. In Materials of the XXIII international. scientific-practical Conf., Brest, February 22, 2019. Brest State University named after A.S., pp. 170-173.

[31] Tsalikova, I.K., Pakhotina, S.V. (2019). Scientific Research on the Issue of Soft Skills Development (Review of the Data in International Databases of Scopus, Web of Science). The Education and science journal, 21(8): 187-207. https://doi.org/10.17853/1994-56392019-7-187-207

[32] Demina, M.A. (2018). Visualization of hieroglyphic information by means of flash animation: a review of foreign teaching experience. Bulletin of the Moscow State Regional University, 1: 108-116.

[33] Saidin, N.F., Abd Halim, N.D., Yahaya, N. (2019). Framework for Developing a Mobile Augmented Reality for Learning Chemical Bonds. International Journal of Interactive Mobile Technologies, 13(7): 54-67. https://doi.org/10.3991/ijim.v13i07.10750

[34] Garaz, I.L. (2020). On the issue of visualization of the learning process. The first step into science: materials of the International Student Conference (May 15, 2020). In two volumes. Volume I. Lugansk: Knita, pp. 28-30.

[35] Sultanova I.V., Vasilenko I.Yu. (2018). Analysis of the most common information visualization techniques in pedagogy and psychology. Problems of modern teacher education, 61(1): 431-435.

[36] Mishchenko, L.I., Mamkin, A.Yu., Mikhailyukov, E.P. (2018). Mind maps as an innovative means of forming the legal culture of students in SPE. Scientific statements. Series: Humanities, 37(3): 518-526.

[37] Liu, Y., Tong, Y., Yang, Y. (2018). The application of mind mapping into college computer programming teaching. Procedia Computer Science, 129: 66-70. https://doi.org/10. 1016/j.procs.2018.03.047

[38] Izhdeneva, I.V. (2016). Mental means of activating the cognitive processes of students. In Materials of the XII International Scientific and Practical Internet Conference "Personal and Professional Development of a Future Specialist". http://www.tsutmb.ru/nauka/inter net-konferencii/2016/lich-i-profrazvitieped/4/izhdeneva.pdf

[39] Plikina, E.B., Kharlamova, V.S. (2017). The main ways of memorizing information in a foreign language. Scientific-methodical electronic journal "Concept", 7: 5.

[40] Chirkova, E., Chernovets, E., Zorina, E. (2019). Visualization method of educational information of the English language grammar communicative teaching in a non-linguistic university. Proceedings of EDULEARN19 Conference, pp. 609-613. https://doi.org/10. 21125/edulearn.2019.0214

[41] Akhmad, R., Sugandi, D., Nandi, N., Ramazani, R. (2018). Infographic Design as Visualization of Geography Learning Media. Earth and Environmental Science, 145: 1-9. https://d oi.org/10.1088/1755-1315/145/1/012011 
[42] Yurchenko, A.A. (2010). The ability to visualize the teaching material as the iccompetence of future teachers of physics. SWorld Journal, 12: 152-159.

[43] Castro-Alonso, J.C., Ayres, P., Sweller, J. (2019). Instructional visualizations, cognitive load theory, and visuospatial processing. In Visuospatial processing for education in health and natural sciences. Springer, Cham, pp. 111-143. https://doi.org/10.1007/978-3-030$\underline{20969-85}$

[44] Anikin, A., Litovkin, D., Kultsova, M., Sarkisova, E., Petrova, T. (2017). Ontology visualization: Approaches and software tools for visual representation of large ontologies in learning. In Conference on Creativity in Intelligent Technologies and Data Science. Springer, Cham, pp. 133-149. https://doi.org/10.1007/978-3-319-65551-2_10

[45] Mokina, A., Khoronko, L. (2020). The role of design and visualization of handouts in the process of training personnel for the agro-industrial complex. E3S Web of Conferences, Vol. 175, pp. 1-7. https://doi.org/10.1051/e3sconf/202017515008

[46] Myrzakulova, K.M. (2016). Teaching methodology of the topic "building diagrams and graphs of mathematical functions" in the EXCEL spreadsheet. Personality, family and society: issues of pedagogy and psychology, 12(69): 10-17.

[47] Hariyadi, S., Corebima, A.D., Zubaidah, S., Ibrohim, I. (2018). Contribution of Mind Mapping, Summarizing, and Questioning in the RQA Learning Model to Genetic Learning Outcomes. Journal of Turkish Science Education, 15(1): 80-88.

[48] Koné, M., May, M., Iksal, S. (2018). Towards a Dynamic Visualization of Online Collaborative Learning. In 10th International Conference on Computer Supported Education, Funchal, Portugal, pp. 205-212. https://doi.org/10.5220/0006687202050212

[49] Kuosa, K., Distante, D., Tervakari, A., Cerulo, L., Fernández, A., Koro, J., Kailanto, M. (2016). Interactive Visualization Tools to Improve Learning and Teaching in Online Learning Environments. International Journal of Distance Education Technologies, 14(1): 1-21. https://doi.org/10.4018/ijdet.2016010101

[50] Omar, M., Ali, D.F., Mokhtar, M., Abdullah, A.H. (2018). The use of virtual environment and augmented reality to support engineering education and enhance visualization skills. Journal of Fundamental and Applied Sciences, 10(6S): 977-988.

[51] Shatri, K., Buza, K. (2017). The Use of Visualization in Teaching and Learning Process for Developing Critical Thinking of Students. European Journal of Social Science Education and Research, 4(1): 71-74.

[52] Rahim, M.H., Siddo, R. (2009). The use of visualization for learning and teaching mathematics. Research in Mathematical Education, 14(3): 496-500.

[53] Kristiyajati, A., Wijaya, A. (2019). The Effectiveness of Visualization of Proofs in Learning Mathematics by Using Discovery Learning Viewed from Conceptual Understanding. Southeast Asian Mathematics Education Journal, 9(1): 37-44. https://doi.org/10.46517/s eamej.v9i1.72

[54] Wilson, K., Solas, E.C., Guthrie-Dixon, N. (2016). A Preliminary Study on the use of Mind Mapping as a Visual-Learning Strategy in General Education Science classes for Arabic speakers in the United Arab Emirates. Journal of the Scholarship of Teaching and Learning, 16(1): 31-52. https://doi.org/10.14434/josotl.v16i1.19181

[55] Ikhsan, J., Sugiyarto, K., Astuti, T. (2020). Fostering Student's Critical Thinking through a Virtual Reality Laboratory, International Journal of Interactive Mobile Technologies, 14(8): 183-194. https://doi.org/10.3991/ijim.v14i08.13069

[56] Swestyani, S., Masykuri, M., Prayitno, B.A., Rinanto, Y., Widoretno, S. (2018). An analysis of logical thinking using mind mapping. In Journal of Physics: Conference Series, 1022(1): 1-8. https://doi.org/10.1088/1742-6596/1022/1/012020 


\section{Authors}

Vorona-Slivinskaya Lubov Grigorievna is a Doctor of Economic Sciences, Professor, Department of Construction Technology, Saint Petersburg State University of Architecture and Civil Engineering (SPbGASU), Saint Petersburg, Russia. Email: lubovvoronasl@rambler.ru, Ly161@yandex.ru

Bokov Dmitry Olegovich is a PhD in Pharmaceutical Sciences, Associate Professor of the Institute of Pharmacy of Sechenov First Moscow State Medical University, Moscow, Russia.

Li Olga Yrevna is a PhD in Medical Sciences, Associate Professor of the Department of Criminal Procedure and Criminalistics, Perm State Research University, Perm Institute of the Federal Penitentiary Service, Perm, Russia.

Article submitted 2020-09-15. Resubmitted 2020-10-18. Final acceptance 2020-10-18. Final version published as submitted by the authors. 